\title{
Synchronous Development of Acute Megakaryoblastic Leukaemia and Disseminated Melanoma following Treatment of a Germ Cell Tumour: A Case Report
}

\author{
Veena Gullapallia ${ }^{a}$ Hannah Hsu $^{b}$ Vanita Bhargava ${ }^{c}$ Peter Presgrave ${ }^{b}$ \\ aPrince of Wales Clinical School, University of New South Wales, Sydney, NSW, Australia; \\ bDepartment of Haematology, Wollongong Hospital, Wollongong, NSW, Australia; \\ 'Department of Anatomical Pathology, Wollongong Hospital, Wollongong, NSW, Australia
}

\author{
Keywords \\ Germ cell tumour - Melanoma - Acute megakaryocytic leukaemia - TP53 - Somatic malignant \\ transformation
}

\begin{abstract}
Somatic malignant transformation of germ cell tumours is a well-described but poorly understood phenomenon. It is characterized by differentiation of pluripotent teratoma cells into somatic tumour cells. Following malignant transformation, the most common histologies are sarcomas and primitive neuroectodermal tumours; however, other subtypes have been recognized including melanoma, leukaemia, and renal cell carcinoma. We report a case of a 38-year-old male who had recently completed treatment for a mediastinal germ cell tumour with teratomatous components. He presented several months after completion of chemotherapy with metastatic lesions in his spine and liver accompanied with severe pancytopenia. He was subsequently diagnosed with acute megakaryoblastic leukaemia (AMKL), and a biopsy of a liver lesion was consistent with metastatic melanoma. This case illustrates the simultaneous development of 2 rare malignant entities: mediastinal germ cell tumour-associated AMKL and somatic malignant transformation to melanoma. It also highlights the importance of close surveillance to detect these metastatic sequelae and the emerging role of tumour sequencing to establish targetable pathways.
\end{abstract}




\section{Introduction}

Extranodal germ cell tumours (GCT) account for 10\% of GCTs and typically arise in midline locations such as the anterior mediastinum and retroperitoneum [1]. It is hypothesized that extragonadal GCTs are derived from primordial germ cells that fail to complete normal migration along the urogenital ridge during embryonal development [2]. Extragonadal GCTs are further classified as seminomatous and non-seminomatous, and non-seminomatous GCTs comprise embryonal carcinomas, teratomas, yolk sac carcinomas, and choriocarcinomas [3].

This dedifferentiation of the somatic components of teratoma in metastatic GCT is found in 3-6\% of untreated patients and in 14\% after platinum-based chemotherapy [4]. The mostcommon histotypes found in teratomatous malignant transformation include rhabdomyosarcoma, PNET, and adenocarcinoma [5]; however, other histologies including melanoma and haematological malignancies, most commonly acute megakaryoblastic leukaemia, are well recognized [6].

\section{Case Presentation}

A 38-year-old male was admitted to the oncology ward with severe left-sided back pain and $30 \mathrm{~kg}$ of weight loss after having recently completed chemotherapy for a mediastinal GCT. Magnetic resonance imaging of the spine demonstrated diffuse loss of the normal fat marrow in the vertebral column, suggestive of marrow replacement and heterogeneous bony lesions involving T1, T9, and L4 (Fig. 1a). A CT of the chest, abdomen, and pelvis looking for further metastatic lesions demonstrated multiple low-density lesions in the liver and the spleen (Fig. 1b), with the largest measuring $4 \times 4.1 \mathrm{~cm}$. The patient was also pancytopenic with a haemoglobin level of 69 g/L (RR 115-165 g/L), a platelet count of $40 \times 10^{9} / \mathrm{L}$ (RR 150-450 $\times 10^{9} / \mathrm{L}$ ), and a neutrophil count of $0.8 \times 10^{9} / \mathrm{L}$ (RR 1.7-7 $\times 10^{9} / \mathrm{L}$ ). Liver function tests were deranged with an ALP of 203 U/L (RR 30-110 U/L), GGT 82 U/L (RR <35 U/L), ALT 13 U/L (RR 10-35 U/L), and AST 72 U/L (RR 10-35 U/L). The lactate dehydrogenase was elevated at 1,968 U/L (RR 150-250 U/L).

The patient had a history of gout and depression with no significant family history. He had recently completed chemotherapy with ifosfamide, cisplatin, and etoposide (VIP) for a mixed GCT after presenting 7 months prior with chest pain and orthopnoea. At the initial presentation, a CT chest revealed a large superior anterior mediastinal mass measuring $16 \times$ $8 \mathrm{~cm}$ that extended into the left lung cavity (Fig. 1c). Biopsies revealed a primary thoracic GCT. The patient completed 2 cycles of VIP chemotherapy, and his beta chorionic gonadotrophin (RR 1-4I U/L) and alpha-fetoprotein (RR 0-8 kU/L) reduced from 5,630 IU/L to $24 \mathrm{IU} / \mathrm{L}$ and $1,224 \mathrm{kU} / \mathrm{L}$ to $103 \mathrm{kU} / \mathrm{L}$, respectively. However, progress imaging demonstrated that the tumour had grown to $17 \mathrm{~cm}$ raising clinical suspicion for growing teratoma syndrome. The patient underwent a thoracotomy and resection of the mass. The removed tumour tissue weighed $3 \mathrm{~kg}$ and measured $25 \times 21 \times 10 \mathrm{~cm}$. Histopathology of the specimen showed features of a treated GCT in addition to a maturing teratoma. He underwent 2 further cycles of VIP chemotherapy and was planned for radiological surveillance.

The presenting admission for back pain occurred 2 months after completion of VIP therapy. The blood film examination at this time demonstrated circulating blasts, large in size with occasional cytoplasmic blebbing (Fig. 2a). Peripheral blood flow cytometry demonstrated a population of blasts positive for CD61, CD56, and CD2 and negative for CD34, HLA-DR, CD117, CD7, and CD33, a phenotype consistent with megakaryoblasts. The bone marrow biopsy demonstrated large areas of marrow necrosis interspersed with areas of medium to large blasts and several dysplastic hyperchromatic megakaryocytes (Fig. 2b, c). There was marked marrow fibrosis. A diagnosis of AMKL was made. Cytogenetic studies revealed the complex hypertriploid karyotype, 59-60<3n>,XY,-X,t(1;3)(q21;q21),add(3)(p11),der(3;14)

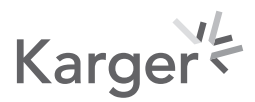



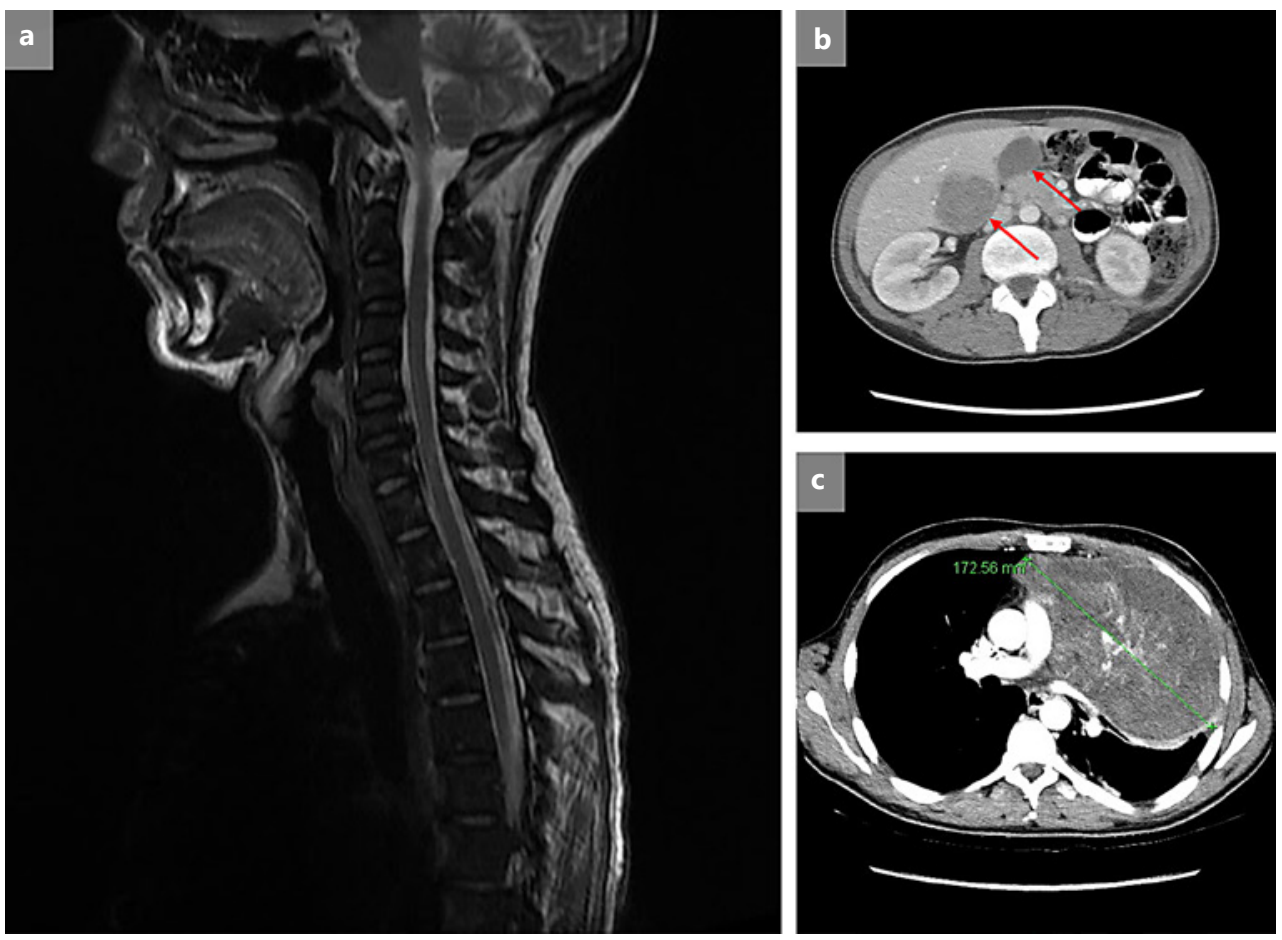

Fig. 1. a T1 MRI sagittal image of the spine demonstrating diffuse loss of the normal fat marrow in the vertebral column. b CT abdomen demonstrating multiple low-density lesions in the liver (see arrows). c CT chest showing a superior anterior mediastinal mass measuring $17 \times 8 \mathrm{~cm}$ extending into the left lung cavity.

(q10;q10),-4, der(6)t(6;12)(p25;q12),-9, del(9)(p13p24), add(10)(p11.2),-11,-12,13, add(14)(p11.1), add(14) (q32), der(14;21) (q10;q10),-15,-16,-17,-18,+19, add(19) (q13.3),+21,+21,-22 [cp20]. Genome sequencing using a commercial myeloid gene amplicon panel detected two deleterious TP53 variants NM000546.5 c469 G > T p.(Val157Phe) and NM000546.5 c641A > G (His214Arg).

Biopsy of the liver lesions was undertaken to establish the nature of these lesions, with clinical suspicion for myeloid sarcoma or disseminated GCT. The histopathology showed necrotic tissue and tumour consisting of large hyperchromatic cells with significant cytoplasm (Fig. 3a). These cells were positive for Melan-A, SOX10, HMB45, and CD117 (Fig. 3b) consistent with melanoma. BRAF inhibitors were considered; however, the tumour proved to be negative for BRAF V600 variants.

In view of the 2 co-existing malignancies with independently poor prognoses, it was decided that conventional chemotherapy for acute leukaemia would be ineffective. The patient and the family decided to forego treatment and opted for palliative measures. The patient passed comfortably in his home soon after discharge from the hospital.

\section{Discussion}

Since first recognized in 1985, multiple studies have described the unique and rare association between haematological malignancies and GCTs [7]. It most commonly manifests as acute megakaryoblastic leukaemia although it has also been associated with myelo-monocytic leukaemia, myelodysplastic syndrome, and essential thrombocytosis [8]. The median time from diagnosis of the GCT to diagnosis of the haematological disease has been observed to be 


\section{Case Reports in Oncology}

\begin{tabular}{l|l}
\hline Case Rep Oncol 2021;14:1638-1644 \\
\hline DOI: 10.1159/000519663 & $\begin{array}{l}\text { @ 2021 The Author(s). Published by S. Karger AG, Basel } \\
\text { www.karger.com/cro }\end{array}$ \\
\hline
\end{tabular}

Gullapalli et al.: Pluripotency of Germ Cell Tumour Giving Rise to Distinct Malignancies
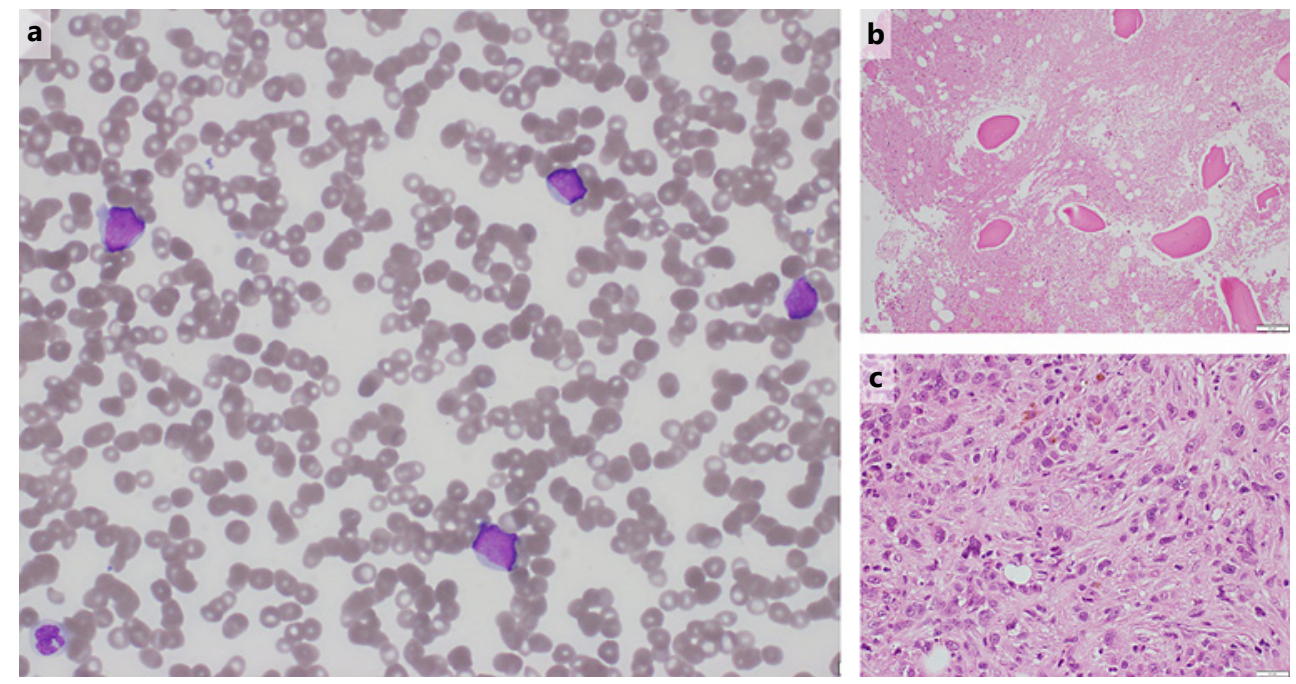

Fig. 2. a PBF 2 months after completion of therapy for GCT. Large circulating agranular blasts with occasional cytoplasmic blebbing are present, $\times 40$ Wright and Giemsa. $\mathbf{b}$ Bone marrow trephine taken at the time the PBF demonstrated widespread bone marrow necrosis, $\times 10$ haemotoxylin and eosin. $\mathbf{c}$ Bone marrow trephine demonstrating replacement of normal marrow with areas of medium to large blasts and dysplastic hyperchromatic megakaryocytes, $\times 40$ haemotoxylin and eosin. PBF, peripheral blood film; GCT, germ cell tumour.
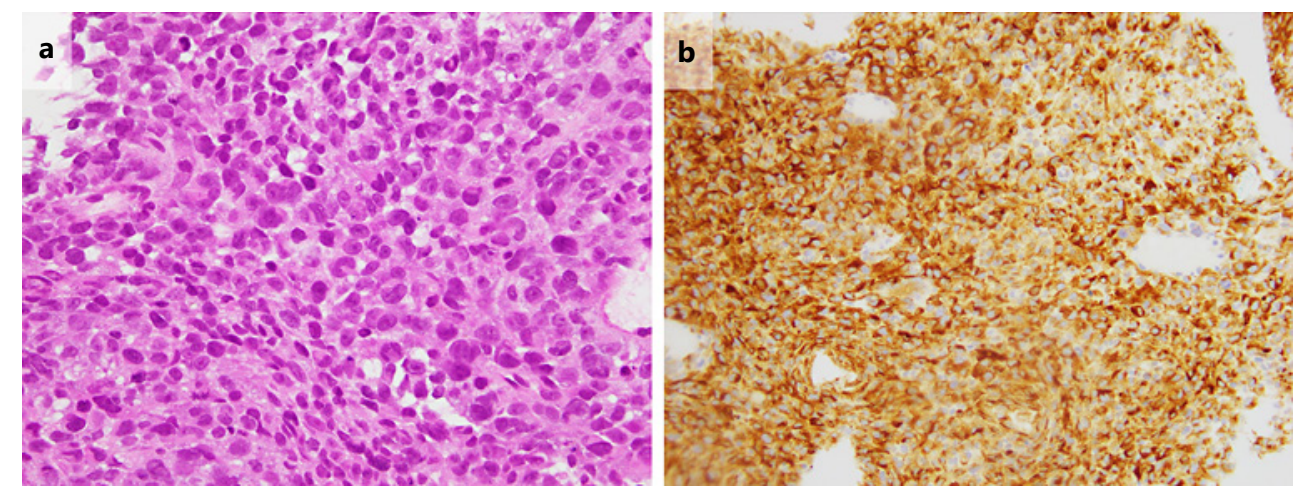

Fig. 3. a Biopsy of liver lesions demonstrating sheets of hyperchromatic large cells with increased cytoplasm, $\times 40$ haemotoxylin and eosin. b Biopsy of the liver lesion with HMB45 stain demonstrating diffuse positivity, $\times 40$.

6 months [6], with rare reports of synchronous presentation [9]. Both cancers are rare and associated with poor outcomes. Isolated de novo AML M7 accounts for $<1 \%$ of all AML cases with a median overall survival reported between 4 and 10 months [10]. The haematological malignancies associated with primary mediastinal GCTs typically behave aggressively, with a median overall survival of only 5 months [6]. Allogeneic stem cell transplant represents the only curative approach for patients; however, very few patients are able to reach transplantation.

Originally, it was hypothesized that these haematological malignancies were secondary to clonal evolution of the GCT. Competing hypotheses included that these malignancies were therapy induced, emerging as a consequence of exposure to cytotoxic agents. Recent developments in cancer genome sequencing have established the presence of common somatic mutations in the PTEN and TP53 genes in these co-existing tumours $[9,11]$ supporting the theory of clonality. Further phylogenetic studies demonstrated that both malignancies are derived from a single clone; however, each harbours unique somatic mutations suggesting divergent 
genetic evolution $[9,12]$. Furthermore, GCT-associated haematological malignancies harbour fewer typical driver mutations which are commonly associated with de novo leukaemias or therapy-induced leukaemias [12]. Conventional cytogenetic and gene sequencing studies of these associated haematological malignancies often reveal complex karyotypic abnormalities, isochrome $12 \mathrm{p}$, and mutations in KRAS, NRAS, TP53, and PTEN genes. These genetic lesions are also frequently seen in GCTs $[9,11,12]$. Furthermore, the presence of TP53 mutations in GCTs is associated with increased risk of developing haematological malignancies [12]. The patient's acute megakaryocytic leukaemia demonstrated a deleterious TP53 mutation; however, isochrome $12 \mathrm{p}$ was notably absent.

Teratomatous components in mediastinal GCTs have been associated with secondary transformation into various subtypes of sarcoma and carcinoma. This secondary transformation into a somatic tumour may occur simultaneously with primary GCTs, after completion of chemotherapy or remotely and are associated with a much poorer prognosis $[13,14]$. Review of the current literature identifies three case reports in which histologically confirmed melanoma has been present in GCT tissue or with synchronous presentation as disseminated disease [15-17]. However, a case of concurrent AMKL and metastatic melanoma has yet to be described. BRAF mutations are commonly present in melanomas of cutaneous origin; however, their incidence at other sites is $10-15 \%$ [18]. Consistent with these findings, our case did not harbour a BRAF mutation which excluded targeted therapy with BRAF inhibitors as a therapeutic option. A case of a mediastinal GCT and associated NRAS-mutated leukaemia has previously reported to have demonstrated in vitro and in vivo sensitivity to the MEK inhibitor, trametinib [19]. Trametinib at present is approved by the US Food and Drug Administration for use in patients with BRAF-mutated melanoma only. However, mutations in the Ras/ Raf/mitogen-activated protein kinase/extracellular-signal-related kinase pathway frequently occur in melanoma, GCT, and associated haematological malignancies. Therapeutic inhibition of this pathway using novel agents such as binimetinib, trametinib, selumetinib, and cobimetinib should be considered when intensive therapeutic regimens remain unsuitable or ineffective.

\section{Conclusion}

Secondary haematological disorders affect 1 in 20 patients with GCT [6], and transformation into somatic tumours remains common. The authors recommend increased clinical surveillance for detection of GCT-associated malignancies and biopsy of suspicious lesions. This case demonstrates the ability for 2 histopathologically distinct tumours to present synchronously in patients with GCT. We also recommend sequencing of tumour tissue to identify contributory oncogenic pathways which can be targeted to improve outcomes in this traditionally prognostically poor disease.

\section{Statement of Ethics}

Written informed consent was obtained from the next of kin for publication of this case report and any accompanying images. This study is exempt from ethics committee approval as it is a case report.

\section{Conflict of Interest Statement}

The authors have no conflicts of interest to declare.

\section{Karger'}




\section{Case Reports in Oncology}

\begin{tabular}{l|l}
\hline Case Rep Oncol 2021;14:1638-1644 \\
\hline DOI: 10.1159/000519663 & $\begin{array}{l}\text { @ 2021 The Author(s). Published by S. Karger AG, Basel } \\
\text { www.karger.com/cro }\end{array}$ \\
\hline
\end{tabular}

Gullapalli et al.: Pluripotency of Germ Cell Tumour Giving Rise to Distinct Malignancies

\section{Funding Sources}

This research did not receive funding.

\section{Author Contributions}

Veena Gullapalli has authorship of the manuscript and contributed to editing of all versions of the manuscript and image acquisition. Hannah Hsu has authorship of the manuscript and edited all versions of the manuscript. Peter Presgrave contributed to editing of all versions of the manuscript, acquisition of data, and confirmation of data integrity. Vanita Bhargava contributed to editing of all versions of the manuscript, acquisition of data, and confirmation of data integrity.

\section{Data Availability Statement}

Data associated with the findings of this study are available upon request from the corresponding author. The data are not publicly available due to privacy and ethical restrictions.

\section{References}

1 Nichols CR, Fox EP. Extragonadal and pediatric germ cell tumors. Hematol Oncol Clin North Am. 1991 Dec 1; 5(6):1189-209.

2 Ariel-Glenn 0, Barkovich J. Intracranial germ cell tumors: a comprehensive review of proposed embryologic derivation. Pediatr Neurosurg. 1996;24(5):242-51.

3 Wick MR, Perlman EJ, Orazi A, et al. Germ cell tumors of the mediastinum. In: Travis WD, Brambilla E, MullerHermelink HK, et al., eds. World Health Organization Classification of Tumours. Pathology and genetics of tumours of the lung, pleura, thymus, and heart. Lyon, France: IARC Press; 2004. p. 198-201.

4 Comiter CV, Kibel AS, Richie JP, Nucci MR, Renshaw AA. Prognostic features of teratomas with malignant transformation: a clinicopathological study of 21 cases. J Urol. 1998 Mar;159(3):859-63.

5 Rebischung C, Cottu PH, Daban A, Terrier-Lacombe MJ, Theodore C, Bonvalot S, et al. Germ-cell tumours containing non germ-cell neoplasms: teratoma with malignant transformation. Urologic Oncol Semin Original Invest. 2001 Nov 1;6:239-42.

6 Hartmann JT, Nichols CR, Droz JP, Horwich A, Gerl A, Fossa SD, et al. Hematologic disorders associated with primary mediastinal nonseminomatous germ cell tumors. J Natl Cancer Inst. 2000 Jan 5;92(1):54-61.

7 DeMent SH, Eggleston JC, Spivak JL. Association between mediastinal germ cell tumors and hematologic malignancies. Report of two cases and review of the literature. Am J Surg Pathol. 1985 Jan 1;9(1):23-30.

8 Nichols CR, Hoffman R, Einhorn LH, Williams SD, Wheeler LA, Garnick MB. Hematologic malignancies associated with primary mediastinal germ-cell tumors. Ann Intern Med. 1985 May 1;102(5):603-9.

9 Lu C, Riedell P, Miller CA, Hagemann IS, Westervelt P, Ozenberger BA, et al. A common founding clone with TP53 and PTEN mutations gives rise to a concurrent germ cell tumor and acute megakaryoblastic leukemia. Cold Spring Harb Mol Case Stud. 2016 Jan 1;2(1):a000687.

10 Hahn AW, Li B, Prouet P, Giri S, Pathak R, Martin MG. Acute megakaryocytic leukemia: what have we learmed. Blood Rev. 2016 Jan;30(1):49-53.

11 Oshrine BR, Olsen MN, Heneghan M, Wertheim G, Daber R, Wilmoth DM, et al. Acquired isochromosome 12p, somatic TP53 and PTEN mutations, and a germline ATM variant in an adolescent male with concurrent acute megakaryoblastic leukemia and mediastinal germ cell tumor. Cancer Genet. 2014;207(4):153-9.

12 Taylor J, Donoghue MT, Ho C, Petrova-Drus K, Al-Ahmadie HA, Funt SA, et al. Germ cell tumors and associated hematologic malignancies evolve from a common shared precursor. J Clin Invest. 2020 Dec 1;130(12):666876.

13 Motzer RJ, Amsterdam A, Prieto V, Sheinfeld J, Murty VV, Mazumdar M, et al. Teratoma with malignant transformation: diverse malignant histologies arising in men with germ cell tumors. J Urol. 1998 Jan; 159(1):133-8.

14 Necchi A, Colecchia M, Nicolai N, Piva L, Catanzaro M, Biasoni D, et al. Towards the definition of the best management and prognostic factors of teratoma with malignant transformation: a single-institution case series and new proposal. BJU Int. 2011 Apr;107(7):1088-94. 
15 McNab P, Quigley B, Mendoza T, Hakam A, Khalil F, Fishman M, et al. The histogenic origin of melanoma arising in respiratory epithelium of a teratomatous germ cell tumor of the mediastinum: an enigma unraveled from an unlikely source. Int J Clin Exp Pathol. 2012 Oct 20;5(9):982-90.

16 Nozaki I, Tone Y, Yamanaka J, Uryu H, Shimizu-Motohashi Y, Sato N, et al. A case of malignant melanoma arising in mediastinal malignant teratoma. Case Rep Pediatr. 2018 Dec 31;2018:1306824.

17 Lee S, Chornenkyy Y, Swete MT, Kim SS, Bharat A, Yang XJ, et al. Malignant melanoma arising in a primary mediastinal germ cell tumor. Pathol Res Pract. 2020 Nov;216(11):153210.

18 Kudchadkar R, Paraiso KH, Smalley KS. Targeting mutant BRAF in melanoma: current status and future development of combination therapy strategies. Cancer J. 2012;18:124-31.

19 Leonard JT, Raess PW, Dunlap J, Hayes-Lattin B, Tyner JW, Traer E. Functional and genetic screening of acute myeloid leukemia associated with mediastinal germ cell tumor identifies MEK inhibitor as an active clinical agent. J Hematol Oncol. 2016 Mar 31;9:31. 